\title{
ORGANIZATION OF TRAUMA CENTRES IN POLAND
}

\section{Agnieszka Szarpak®}

Lazarski University, Warsaw, Poland

\begin{abstract}
The organization of the medical emergency system in Poland assumes assistance to persons in danger of life and health at various stages, starting with the onset of their first symptoms. The witnesses of the event who undertake rescue operations - begin first aid and inform the emergency medical team - play a key role. The management of the trauma patient by staff requires knowledge of the patient's assessment, as well as the ability to qualify the patient to the trauma centre according to criteria and age group, as there are two types of trauma centres: for adults and for people under 18 years of age, called a traumatic centre for children.
\end{abstract}

KEY WORDS: trauma centre, trauma centre for children, injury

Disaster Emerg Med J 2019; 4(2): 55-59

\section{INTRODUCTION}

High-energy trauma, especially those due to transport communication, is an enormous challenge for modern emergency medicine, considering that this is the third cause of death in the world [1]. Falls from heights also belong to those which are problematic, considering that there is a close relationship between the height and the injuries sustained, which unfortunately are more lethal and complicated in the rescue procedure if the victim falls from higher heights of a given structure [2]. The modern medical emergency system is designed to not only organize a network of ambulances and rescue helicopters but also to create appropriate emergency departments in which emergency medicine activities will be carried out. In addition to hospital emergency departments, in the Polish system of emergency medical services, dedicated to patients with the most severe injuries were created, so-called trauma centres, dividing patients additionally into adult centres and children's centres. The age-division of patients is related to the specificity of treatment of injuries in adults and the diversity resulting from childhood. Injuries and wounds are prevalent in children and remain a significant cause of mortality and morbidity [3].

\section{Trauma centres in the system of the State Medical Rescue}

According to the definition in the Act on State Emergency Medical Services, the trauma centre is a functionally separated part of the hospital in which the hospital emergency department operates, in which sections of the specialized units relate to each other organizationally and in their scope of tasks in a manner allowing for quick diagnosis and treatment of a traumatic patient [4]. It should be made clear that a traumatic patient is a person who is in a state of immediate health risk resulting from the action of an external factor, which results in substantial, multiple or multi-organ injuries. These definitions concern those over 18 years of age; as such, these solutions are dedicated to a group of patients strictly defined by age.

In the Trauma Centre, health services are provided to a trauma patient by a team of doctors who hold the title of a specialist, and their collective name is a "traumatic team". According to the adopted assumptions, it secures, in terms of health services, a population of no less than 1 million inhabitants, inhabiting an area that allows reaching the trauma centre within 1.5 hours from the place of the event. 
Taking into account the functional structure that the Trauma Centre must contain, it ensures the operation in its composition of specialized treatment departments and diagnostic laboratories, which include:

- anaesthesiology and intensive care unit, which ensures the availability of at least two intensive care stations to provide health services to a trauma patient,

- operating block, which ensures constant readiness of at least one operating room to provide health services to a trauma patient,

- diagnostic laboratory and treatment endoscopy, open 24 hours a day,

- departments such as general surgery or multi-organ injuries, orthopaedics and traumatology of the motor organ, neurosurgery or general surgery with the profile of neuro traumatology, vascular surgery or general surgery with a vascular surgery profile.

Part of the Trauma Centre is a diagnostic and imagining laboratory operating 24 hours a day, and the availability of health services provided by a physician holding the title of a specialist in the field of cardiac surgery or thoracic surgery must not exceed 30 minutes since the circumstances justifying the provision of such services. Another infrastructure requirement is the necessity of having an airstrip or airport for a rescue helicopter, located at such a distance that it would be possible to accept a traumatic patient, without the mediation of specialized means of a sanitary transport [4].

The trauma team consists of at least:

- a doctor in the hospital emergency department with the title of an emergency medicine specialist;

- a doctor or doctors holding the title of a specialist or a second-degree specialization in the field of medicine applicable to the treatment of a traumatic patient, in particular general surgery, orthopaedics and traumatology, neurosurgery or vascular surgery;

- a physician holding the title of a specialist in the field of anaesthesiology and intensive care or a doctor with a second-degree specialization in the field of anaesthesiology or anaesthesiology and resuscitation or anaesthesiology and intensive care.

It is important to emphasize that the head of the trauma team directs the entire trauma team [5].

\section{Classification of the patient for the Trauma Centre}

For the reasons that specialized centres have the task of reducing the mortality of the most seriously injured persons, it remained necessary to adopt criteria for all members of the Medical Rescue Team to follow. These criteria ensure that rescue teams could directly and reasonably direct these patients from the place of the accident, omitting other centres that do not meet the criteria for patients with complicated injuries. A person in a state of emergency is eligible for the treatment at a trauma centre that meets the following criteria:

Presence of at least two of the following anatomical injuries:

- penetrating head or torso wounds or blunt injuries with signs of damage to the internal organs of the head, chest, and abdomen,

- limb amputation above the knee or elbow,

- extensive crushing of the limbs,

- damage to the spinal cord,

- limb fracture with damage to vessels and nerves,

- fracture of at least two proximal bones of long limbs or pelvis;

And, at least two of the following physiological parameters disturbances:

- systolic blood pressure equal to or below $80 \mathrm{~mm} \mathrm{Hg}$,

- heart rate at least 120 per minute,

- respiratory rate below 10 or over 29 per minute,

- Glasgow level of awareness (GCS) equal to or below 8 ,

- arterial oxygen saturation equal to or below $90 \%[5]$.

Until now, the transport of a trauma patient was to the nearest Hospital Emergency Department, where continuing rescue operations would take place. Numerous studies and mortality analyses, however, showed completely different results. It turned out that even prolonged transport from the place of incident to the Trauma Centre, due to the injuries and their complexity, such a patient has a much better chance of survival than caring for the patient injuries in the nearest Hospital Emergency Department [6]. It is important to note that competent and skilful use of trauma centre resources helps to reduce morbidity and mortality while saving medical costs [7].

\section{Paediatric Traumatic Center}

The term, traumatic centre, specifies a functionally separated part of the hospital in which a hospital emergency department operates, in which parts of the specialized departments relate to each other and the scope of tasks, in a manner allowing quick diag- 
nosis and treatment of a paediatric trauma patient. A child trauma patient is a person under 18 years of age, who is in a state of immediate health risk caused by the action of an external factor, which results in severe, multiple or multi-organ injuries [4]. Due to the anatomical complexity of children, the specificity of their treatment, as well as the types of injuries they have suffered, it was considered reasonable to create centres in which underage patients will receive comprehensive assistance. In the paediatric trauma centre, health services are provided to a paediatric trauma patient by a team of doctors holding the titles of specialists, having the common name of a "paediatric trauma syndrome". The trauma centre for children accepts, comprehensively diagnoses and treats the paediatric trauma patient in a broad range, according to the current medical knowledge in the treatment of severe, multiple or multiple organ injuries, and its structure is the same as for a trauma centre dedicated to adults. Children's trauma syndrome includes at least:

- a doctor in the hospital emergency department who is a physician of the system,

- physicians with the titles of specialists or a second-degree specialization in the field of medicine applicable to the treatment of paediatric trauma patient, in particular, paediatric surgery, orthopaedics and traumatology of the musculoskeletal system and neurosurgery,

- a physician holding the title of a specialist in the field of anaesthesiology and intensive care or a doctor with a second-degree specialization in the field of anaesthesiology or anaesthesiology and resuscitation, or anaesthesiology and intensive care. The head of the trauma team leads the entire paediatric trauma team [8].

\section{Classification of the patient to the Paediatric Traumatic Centre}

the head of the Emergency Medical Team qualifies an underage patient who is in a state of emergency health risk for the treatment in the centre if their condition meets the following criteria:

The occurrence of at least one of the following anatomical injuries:

- $\quad$ penetrating head or torso wounds or blunt trauma with signs of damage to the internal organs of the head, chest or abdomen,

- limb amputation above the wrist or ankle,

- extensive crushing of the limb,

- damage to the spinal cord,
- unstable chest,

- limb fracture with damage to vessels or nerves,

- fracture of at least two proximal bones of long limbs (humerus, femur) or pelvis,

As well as accompanying at least two of the following disorders of physiological parameters set out in the Annex to the Regulation:

- a decrease in systolic blood pressure below the value (Tab. 1),

- deviation of the heart rate beyond the range (Tab. 2),

- deviation of the number of breaths outside the range indicated in (Tab. 3),

- the state of consciousness assessed according to the Glasgow Coma Scale (GCS) or the Child Coma Scale (CCS) criteria for children up to 3 years of age, not more than 13 points, arterial oxygen saturation not more than $90 \%$.

The next criteria to be followed by qualifying a juvenile patient to the trauma centre are:

- the occurrence of a multi-organ injury or death of another person in the same incident,

Table 1. Minimum systolic blood pressure, depending on the age of the child

\begin{tabular}{|l|l|l|}
\hline \multicolumn{1}{|c|}{ Nr. } & \multicolumn{1}{|c|}{ Age } & \multicolumn{2}{c|}{ Systolic blood pressure } \\
\hline 1 & 1 & 65 \\
\hline 2 & $2-5$ & 70 \\
\hline 3 & $6-12$ & 80 \\
\hline 4 & $>12$ & 90 \\
\hline
\end{tabular}

Table 2. Range of heart rate depending on the age of the child

\begin{tabular}{|l|l|l|}
\hline \multicolumn{1}{|c|}{ Nr. } & \multicolumn{1}{|c|}{ Age } & \multicolumn{1}{c|}{ Systolic blood pressure } \\
\hline 1 & 1 & $110-150$ \\
\hline 2 & $2-5$ & $90-130$ \\
\hline 3 & $6-12$ & $70-110$ \\
\hline 4 & $>12$ & $60-100$ \\
\hline
\end{tabular}

Table 3. Range of the number of breaths per minute depending on the age of the child

\begin{tabular}{|l|l|l|}
\hline \multicolumn{1}{|c|}{ Nr. } & \multicolumn{1}{|c|}{ Age } & \multicolumn{1}{|c|}{ Systolic blood pressure } \\
\hline 1 & 1 & $30-40$ \\
\hline 2 & $2-5$ & $20-30$ \\
\hline 3 & $6-12$ & $15-25$ \\
\hline 4 & $>12$ & $12-20$ \\
\hline
\end{tabular}


- falling out of a motor vehicle, crushing or falling from a height above 3 meters,

- at the time of extracting this person from the vehicle, the rubble or debris is above 20 minutes, despite the lack of visible anatomical anomalies and significant disturbances of physiological parameters present in that person, found at the scene of the event.

Given the above, it is essential to note that the criteria dedicated to children are more extensive than in the case of adults. It must be remembered, however, that the main elements that must be analysed by the emergency medical personnel are the assessment of the mechanism of injury.

\section{Conclusion}

Injuries are the leading cause of death before the age of 40 and the third most common cause of death in the world after cardiovascular diseases and cancers [9]. The organization of rescue systems is a dynamic and continuously modifiable process of every state management system. With consideration to one of the fundamental rights of the patient, the access to immediate health services due to a threat to health or life, the entire system must focus on the possibility of creating treatment conditions that are maximally matched to his or her health, as well as the law to health services meeting the requirements of current medical knowledge [10].

The necessity to establish specialized facilities to treat patients who have suffered severe injuries is due to the need of reducing mortality in this group of patients (Fig. 1). The emergence of appropriate systems bringing together teams of specialists as well as housing and hardware resources in one place noted is a drop in mortality and as a result, increasing the effectiveness of treatment in trauma centres [11]. An analysis of the intervention of Medical Emergency Teams also showed that craniocerebral

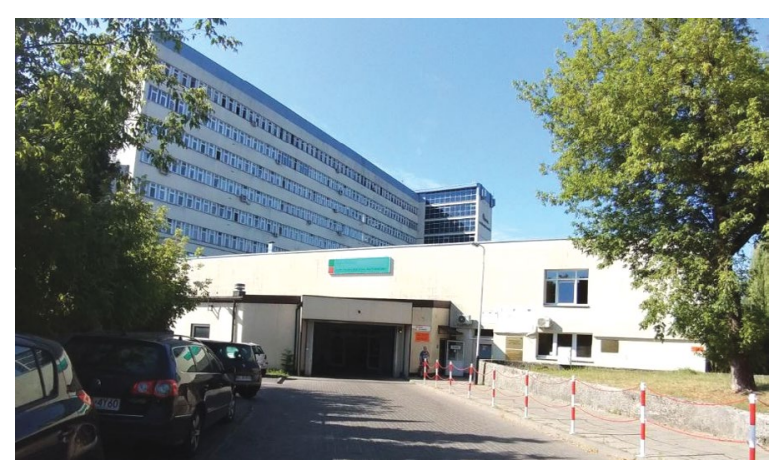

FIGURE 1. Example of Trauma Centre injuries are the most common and can often lead to a direct threat to life [12]. Since this analysis, there has been a continuous decrease in the mortality of these patients when they reach the reference centre in the treatment of severe bodily injury [7].

The specificity of treating children and their qualification for trauma centres is what directly caused the creation of centres for these age groups. World research shows that even the most trivial and less visible injuries can contribute to the induction of a life-threatening condition, unlike an adult. Intra-abdominal trauma occurs in approximately $25 \%$ of paediatric patients, including major trauma, and is the most common cause of unrecognized fatal injury in children. This trauma is usually dull, and the spleen is the most common damaged organ [13]. Based on this data, such a patient should deal only in the children's traumatic centre. It also shows the need for continuous analysis and evaluation of the injury mechanism, which has a direct impact on mortality [14].

Medical emergency teams should know the rules for assessing trauma injured, and to qualify those patients to trauma centres due to the complexity of the further treatment process. Currently functioning trauma centres are highly specialized health care facilities operating within the framework of the State Medical Rescue system and are an integral part of the health security system.

\section{REFERENCES}

1. Goniewicz K, Goniewicz M, Pawłowski W, et al. Road safety in Poland: magnitude, causes and injuries. Wiad Lek. 2017; 70 (2 pt 2): 352-356, indexed in Pubmed: 29059658.

2. Kusior ME, Pejka K, Knapik $M$, et al. Analysis of the nature of injuries in victims of fall from height. Arch Med Sadowej Kryminol. 2016; 66(2): 106124, doi: 10.5114/amsik.2016.64709, indexed in Pubmed: 28144931.

3. Holland AJa, Soundappan SSv. Trauma hazards in children: An update for the busy clinician. J Paediatr Child Health. 2017; 53(11): 1096-1100, doi: 10.1111/jpc.13603, indexed in Pubmed: 28665528.

4. Ustawa z dnia 8 września 2006 r. o Państwowym Ratownictwie Medycznym. (Dz. U. $2006 \mathrm{Nr} 191$ poz. 1410).

5. Rozporządzenie Ministra Zdrowia z dnia 18 czerwca 2010 r. w sprawie centrum urazowego. (Dz.U. $2010 \mathrm{nr} 118$ poz. 803).

6. Dijkink S, Nederpelt $\mathrm{C}$, Krijnen $\mathrm{P}$, et al. Trauma systems around the world: A systematic overview. J Trauma Acute Care Surg. 2017; 83(5): 917-925, doi: 10.1097/TA.0000000000001633, indexed in Pubmed: 28715361.

7. Faul M, Sasser SM, Lairet J, et al. Trauma center staffing, infrastructure, and patient characteristics that influence trauma center need. West J Emerg Med. 2015; 16(1): 98-106, doi: 10.5811/westjem.2014.10.22837, indexed in Pubmed: 25671017. 
8. Rozporządzenie Ministra Zdrowia z dnia 25 stycznia 2016 r. w sprawie centrum urazowego dla dzieci. (Dz.U. 2016 poz. 145).

9. Szarpak L, Madziała M. Chest injuries based on medical rescue team data. Pol Przegl Chir. 2012; 84(5): 247-252, doi: 10.2478/v10035012-0041-0, indexed in Pubmed: 22763300.

10. Ustawa z dnia 6 listopada 2008 r. o prawach pacjenta i Rzeczniku Praw Pacjenta. (Dz. U. 2009 Nr 52 poz. 417).

11. Siman-Tov M, Radomislensky I, Peleg K. ITG. Reduction in trauma mortality in Israel during the last decade (2000-2010): the impact of changes in the trauma system. Injury. 2013; 44(11): 1448-1452, doi: 10.1016/j.injury.2012.08.054, indexed in Pubmed: 23021368.
12. Szarpak L, Madziała M. Epidemiology of cranio-cerebral injuries in emergency medical services practice. Pol Przegl Chir. 2011; 83(12): 646-651, doi: 10.2478/v10035-011-0103-8, indexed in Pubmed: 22343200.

13. Lynch T, Kilgar J, Al Shibli A. Pediatric Abdominal Trauma. Curr Pediatr Rev. 2018; 14(1): 59-63, doi: 10.2174/1573396313666170815100 547, indexed in Pubmed: 28814248.

14. Reihani $H$, Pirazghandi $H$, Bolvardi $E$, et al. Assessment of mechanism, type and severity of injury in multiple trauma patients: $A$ cross sectional study of a trauma center in Iran. Chin J Traumatol. 2017; 20(2): 75-80, doi: 10.1016/j.cjtee.2016.02.004, indexed in Pubmed: 28363517. 